\title{
Staphylococcus aureus on the hair
}

\author{
W. C. NOBLE \\ From the Bacteriology Department, Institute of Dermatology, St. John's Hospital \\ for Diseases of the Skin, London
}

SYNOPSIS Staphylococcus aureus was found to be present on the hair of about $10 \%$ of people having no hospital contact and on that of about $50 \%$ of patients with skin diseases.

The 'resident' carrier rate was higher in patients with eczema and psoriasis than in others and $\overrightarrow{0}$ appeared to be related to carriage of the organisms on the skin.

Much of the 'transient' carriage could be attributed to contamination from other sources in the ward.

The carriage of Staphylococcus aureus on the hair was reported by Summers, Lynch, and Black (1965) who found that about $37 \%$ of 686 patients and staff of a general hospital carried staphylococci on their hair. Only a small proportion of those who were both nasal and hair carriers yielded the same strain at both sites and it seems probable therefore that much of the carriage was simply contamination of the hair from other sources. In view of the propensity of some patients with diseases of the skin to be heavily colonized with Staph. aureus, it appeared worth extending the observations of Summers et al. to see whether in-patients in a hospital for skin diseases had a higher carrier rate than others. These observations form part of a more extensive investigation of cross infection in dermatological wards. In the course of other studies on the carriage of microorganisms on the skin, a number of persons having no hospital contact were investigated, and to complete the picture, in-patients at another hospital were sampled.

\section{METHODS}

Since many of the individuals sampled were seen away from the hospital, it was not practicable to use the direct contact plate method of Summers et al. (1965). Samples were taken by rubbing the hair with a piece of sterile velvet which was subsequently pressed onto the surface of an agar plate. Only four of the 1,250 samples taken by this method failed to yield growth but when 58 patients with dermatitis were subsequently sampled using both techniques it was obvious that the direct contact method yielded far higher total counts than the velvet. Staph. aureus was not recovered by either method from 34 of these 58 duplicate samples but was recovered from both in 17 cases; Staph. aureus was recovered on five occasions from the direct plate alone and on two occasions from

Received for publication 6 July 1966. the velvet alone. In all instances where the staphylococcio were recovered by only one method, the number of 3 staphylococcal colonies on the culture plate was less thand six.

An attempt was made to distinguish between the 'transient' and 'resident' flora of the skin and hair on aos quantitative basis. When cultures yielded six or more colonies of staphylococcus the carriage was regarded aso 'resident' and when fewer than six as 'transient'. This level was, of course, arbitrary but in practice it has been found that although the majority of nasal or perinealo carriers yield far more than six colonies of staphylococcio from these sites, it is rare to recover more than six colonies from any other skin site unless the person has a 3 skin disease such as eczema or impetigo. On this basis staphylococci on eczematous skin or in the nose or perineum would generally be regarded as resident whilst those on normal skin would normally rank as transient $\frac{\pi}{0}$ A higher threshold would clearly be needed if a more efficient method than swabbing were used to recover the organisms.

Blood agar or serum agar containing phenol phthalein phosphate (Barber and Kuper, 1951) was used throughout the study for samples from hair. Data on the carriage of microorganisms in the nose and perineum and on the $D$ skin of the sternum were available for many patients with을. skin disease on the same occasion as the sample of hair. $N$ Swabs from these sites were always inoculated on blood ${ }^{\circ}$ agar. The word staphylococcus is used in this paper to N mean the coagulase-positive Staphylococcus aureus.

\section{RESULTS}

Patients with skin diseases had higher resident and $\stackrel{\oplus}{?}$ transient carrier rates on the hair than did the others (Table I); these results are based on samples taken $\frac{}{\mathrm{T}}$ with velvet only. The higher resident carrier rate was most marked. There do not appear to be any signi- $₫$ ficant differences between the other groups of normalo 
TABLE I

CARRIAGE OF Staph. aureus ON HAIR

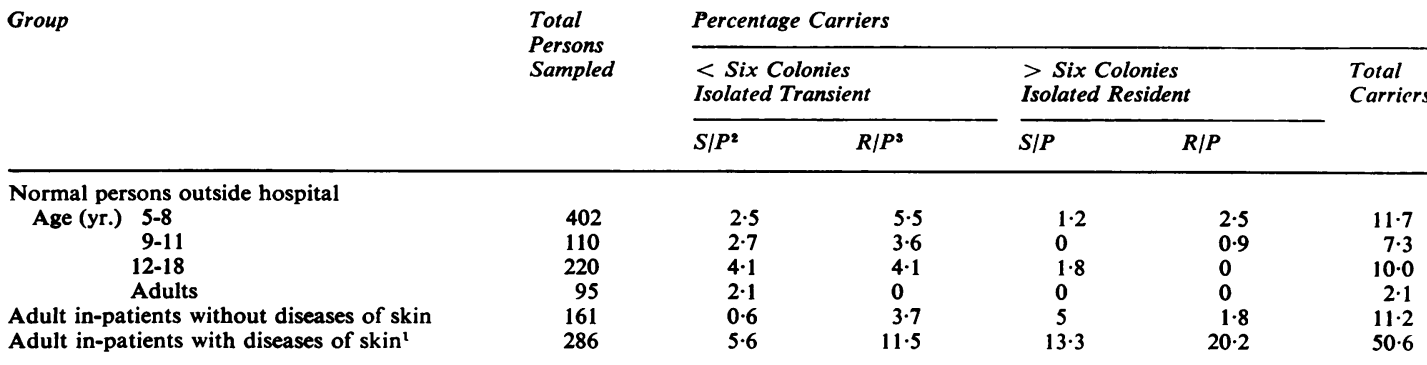

This table is based on results obtained with velvet only.

$2 S / P$ indicates a strain sensitive to penicillin.

${ }^{3} R / P$ indicates a strain resistant to penicillin.

TABLE II

CARRIAGE OF Staph. aureus ON HAIR IN RELATION TO NASAL AND SKIN CARRIAGE IN PATIENTS WITH SKIN DISEASE

\begin{tabular}{|c|c|c|c|c|c|c|}
\hline \multirow{3}{*}{$\begin{array}{l}\text { Carrier } \\
\text { Status }\end{array}$} & \multirow{3}{*}{$\begin{array}{l}\text { Total } \\
\text { No. of } \\
\text { Patients }\end{array}$} & \multicolumn{5}{|c|}{ Number and Percentage with Hair Carriage } \\
\hline & & \multicolumn{2}{|c|}{ Carried Same Strain ${ }^{1}$} & \multicolumn{2}{|c|}{ Carried Different Strain ${ }^{1}$} & \multirow{2}{*}{$\begin{array}{l}\text { Total } \\
\text { Carriers }\end{array}$} \\
\hline & & $<$ Six Colonies & $>$ Six Colonies & $<$ Six Colonies & $>$ Six Colonies & \\
\hline $\begin{array}{l}\text { Nasal only } \\
\text { Skin only } \\
\text { Nasal and skin } \\
\text { Non-carriers }\end{array}$ & $\begin{array}{r}26 \\
9 \\
41 \\
54\end{array}$ & $\begin{array}{l}2(8 \%) \\
4(45 \%) \\
5(12 \%) \\
7(13 \%)\end{array}$ & $\begin{array}{r}4(15 \%) \\
1(11 \%) \\
20(49 \%) \\
8(15 \%)\end{array}$ & $\begin{array}{l}3(11 \%) \\
0 \\
2(5 \%) \\
-\end{array}$ & $\begin{array}{l}4(15 \%) \\
2(22 \%) \\
5(12 \%) \\
-\end{array}$ & $\begin{array}{r}13(50 \%) \\
7(78 \%) \\
32(78 \%) \\
15(28 \%)\end{array}$ \\
\hline Total² & 130 & $18(14 \%)$ & $33(25 \%)$ & $5(4 \%)$ & $11(9 \%)$ & $67(52 \%)$ \\
\hline
\end{tabular}

1Strains regarded as same or different on basis of antibiotic resistance only.

${ }^{2}$ Full details of nasal and skin carriage were not available for all patients.

persons or patients without skin disease. This is curious in view of the high carrier rate found by Summers et al. (1965) among patients but may be attributable to the difference in methods used. In this series there was a rather low nasal carrier rate for Staph. aureus (24\%) in the patients without skin disease and this may be reflected in the low carrier rates for staphylococci in hair.

In Table II the results for patients with skin diseases are subdivided according to carrier status (based only on those patients for whom full data were available). Patients who were skin carriers of Staph. aureus had much higher carrier rates of staphylococci on the hair than those who were nasal carriers only or were not carriers. This supports the expectation that patients with skin disease might have a high 'true' carrier rate. Patients with 'eczema' and psoriasis had the highest carrier rates, both on the skin and hair, and those with ulcers the lowest rates (Table III). Patients in the 'other' group were suffering from a wide variety of skin diseases and so little importance can be attached to these results. The total carriage rate of staphylococci on the hair and skin was lower amongst the females than the males but
RELATION OF HAIR CARRIAGE TO DIAGNOSIS OF DISEASE

\begin{tabular}{|c|c|c|c|c|c|}
\hline \multirow[t]{3}{*}{ Diagnosis } & \multirow{3}{*}{$\begin{array}{l}\text { Total } \\
\text { No. of } \\
\text { Patients }\end{array}$} & \multicolumn{4}{|c|}{ Percentage Carriers of Staph. aureus } \\
\hline & & \multicolumn{2}{|c|}{ Hair Carriers } & \multirow{2}{*}{$\begin{array}{l}\text { Total } \\
\text { Hair } \\
\text { Carriers }\end{array}$} & \multirow{2}{*}{$\begin{array}{l}\text { Skin } \\
\text { Carriers }\end{array}$} \\
\hline & & $\begin{array}{l}<\text { Six } \\
\text { Colonies }\end{array}$ & $\begin{array}{l}>\text { Six } \\
\text { Colonies }\end{array}$ & & \\
\hline $\begin{array}{l}\text { 'Eczema' } \\
\text { Psoriasis } \\
\text { Stasis ulcers } \\
\text { Other } \\
\text { Total }\end{array}$ & $\begin{array}{r}35 \\
36 \\
20 \\
39 \\
130\end{array}$ & $\begin{array}{l}26 \\
16 \cdot 5 \\
15 \\
10 \cdot 5 \\
17\end{array}$ & $\begin{array}{l}54 \\
44 \cdot 5 \\
5 \\
20 \\
34\end{array}$ & $\begin{array}{l}80^{2} \\
61 \\
20 \\
31 \\
51 \cdot 5\end{array}$ & $\begin{array}{l}69 \\
28 \\
10 \\
36 \\
50\end{array}$ \\
\hline
\end{tabular}

'Two of the non-carriers of staphylococci yielded very high counts of coliforms from the hair.

this is associated with differences in the type of patients admitted to the wards. There were, for example, four eczema patients $(10.5 \%)$ in a total of 38 females and 31 eczema patients (34\%) amongst the 92 male patients.

In common with the experience of Summers et al., coliform organisms were also isolated from the hair of many persons, but except on one occasion the carrier rate in our series did not exceed $10 \%$. 


\section{DISCUSSION}

The total carrier rate for both staphylococci and coliform organisms was lower in this investigation than in that reported by Summers et al. (1965). This may be attributed to the difference in techniques and also to the difference in the populations sampled. Amongst the patients with skin diseases were many who yielded almost pure, confluent growths of staphylococci on the agar medium even by the velvet replica technique. Before the work of Summers et al., no account had been taken of the hair as a source of staphylococci but it is now clear that this might form a considerable reservoir of organisms at least in dermatological wards. From the results of phage typing and antibiotic sensitivity tests it is clear that much of the transient 'carriage' was contamination from some common source in the ward. On one occasion nine of 17 patients in one ward carried the same organism (resistant to penicillin and strepto- mycin, sensitive to tetracycline and chloramphenicol: phage type $6 / 53 / 75$ at 1,000 RTD) on the hair, two patients carried it in the nose but only one of these (a psoriatic) carried it on the skin. He was a 'residenE carrier' on the chest, thigh, shin, shoulder, and wrist for about two weeks during which time the dispersan occurred and it seems likely that he was the sourcen of infection.

I am indebted to the consultants at St. John's HospitaL and to the physicians and surgeons at the Bromptorn Hospital for permission to examine their patients
bacteriologically.

Many people took part in the surveys outside the hospital, but I am particularly indebted to Miss Pamela MWhite for technical assistance.

\section{REFERENCES}

Barber, M., and Kuper, S. W. A. (1951). J. Path. Bact., 63, 65. Summers, M. M., Lynch, P. F., and Black, T. (1965). J. clin. Path. 18, 13. 